\title{
Religión e integración: Creencias y prácticas de los inmigrantes
}

\author{
OLGA ODGERS ORTIZ*
}

RESUMEN: Las creencias y prácticas religiosas pueden constituir un importante recurso en el proceso de integración de los migrantes, sin embargo, la forma y la dirección en que dichos recursos son empleados, puede variar significativamente, incluso entre grupos de inmigrantes procedentes de un mismo país de origen, establecidos en una misma región, y que profesaban la misma religión al iniciar la migración. A partir de la experiencia de tres grupos de inmigrantes mexicanos establecidos en la región metropolitana de Los Ángeles, mostramos la relevancia de la especificidad en la práctica religiosa y organizativa en las localidades de origen, para comprender los caminos elegidos por los migrantes para movilizar prácticas y creencias en la reconfiguración de su relación con las localidades de origen y destino.

PALABRAS CLAVE: integración, religión, conversión religiosa, transnacionalismo, etnicidad.

ABSTRACT: Religious practices and beliefs can constitute an important resource in the integration process of migrants, however, the form and direction in which such resources are utilized may vary significantly even among migrant groups coming from the same country, established within the same region and who used to practice the same religion when starting their migration process. Three groups of Mexican immigrants living in the metropolitan area of Los Angeles have been tracked to emphasize how relevant religious practices are at the point of origin. Such relevance helps to understand the pathways chosen by the migrants so they can restructure practices and beliefs when adapting to their new environment.

KEY WORDS: Integration, religion, religious conversion, transnationalism, ethnicity.

* Investigadora de El Colegio de la Frontera Norte, México. Directora de la revista Migraciones Internacionales. 


\section{INTRODUCCIÓN}

$7 \mathrm{n}$ los debates recientes sobre la incorporación de los inmigrantes a las sociedades receptoras, la integración cultural —y más específicamente la alteridad religiosa - ha sido uno de los temas que ha resultado más controversial y que ha desatado las discusiones más apasionadas. En los medios de comunicación e incluso en el ámbito académico (Huntington, 2004), las creencias y prácticas religiosas de «los otros» han sido presentadas como diferencias esenciales, no negociables y no superables, por lo que pondrían en peligro la identidad misma de las sociedades receptoras.

Esta visión fatalista de la alteridad religiosa, presente en diversas sociedades industriales avanzadas, adquiere matices cambiantes, con momentos de exacerbación específicos. En el contexto estadounidense contemporáneo, si bien es cierto que el Islam ha sido construido como la alteridad religiosa más radical —especialmente a partir del 11 de septiembre de 2001—, incluso los migrantes mexicanos católicos han sido clasificados como inasimilables por intelectuales tan renombrados como Samuel Huntington, quien en el libro elocuentemente titulado Who we are? The challenges of America's Nacional Identity manifiesta que la incapacidad de los hispanos para asimilarse significaría un riesgo mayor para la identidad estadounidense (Huntington, 2004). Dentro de la retórica presentada en dicho libro, Huntington sostiene que «los mexicanos y otros latinos no se han asimilado a la cultura principal de Estados Unidos, formando en cambio sus propios enclaves políticos y lingüísticos - de Los Ángeles a Miami-y rechazando los valores anglo-protestantes que construyeron el sueño americano» (Huntington, 2004: 223).

Sin embargo, más allá de esta retórica alarmista, diversos autores (Herberg [1955] 1985); Warner, 1993; Hirschman, 2004; Levitt, 2004 y 2008) han mostrado que las creencias, prácticas e instituciones religiosas, si bien en ocasiones son fuente de conflicto, también han constituido un recurso relevante en los procesos de integración de los inmigrantes.

Desde la obra clásica de Herberg ([1955] 1985), se enfatizaba la importancia de las religiones de los inmigrantes — católicos, protestantes y judíos- 
en su experiencia de asimilación, destacando que la paulatina desafiliación étnica - la estadounidización de los inmigrantes - no implicaría, sin embargo, la pérdida progresiva de la diversidad religiosa. Es decir, desde la perspectiva de Herberg, la sociedad estadounidense no estaría caracterizada por un melting pot, sino por la progresiva estadounidización del componente religioso aportado por la inmigración, mismo que perduraría a través de las generaciones.

Esta misma línea es desarrollada, posteriormente, por diversos teóricos, dentro de la corriente crítica que cuestiona el paradigma de la secularización. Así, por ejemplo, a finales del siglo pasado, Warner (1993) proponía que, a diferencia de otras sociedades europeas previamente estudiadas, Estados Unidos se caracterizaría, desde su formación, por la preeminencia de un campo religioso diverso, regido por la lógica de un mercado abierto, y no por la de un monopolio religioso (Warner, 1993: 1044). La diversidad religiosa - y no la secularización progresiva - habría caracterizado, entonces, a la modernidad estadounidense, manteniéndose esta singularidad hasta la actualidad.

Esta perspectiva será retomada posteriormente, con relación a las nuevas migraciones, añadiendo a la discusión las tensiones existentes entre las sociedades receptoras y sus nuevos inmigrantes. Así, por ejemplo, Hirschman sugiere que «la creación de una iglesia inmigrante frecuentemente constituye un refugio para las comunidades étnicas ante la hostilidad y la discriminación de las sociedades amplias, y les provee de oportunidades para la movilidad económica y el reconocimiento social» (Hirschman, 2004: 1206). Esta especificidad de las sociedades multiculturales contemporáneas permitiría comprender mejor el surgimiento de las iglesias étnicas, que constituirían entonces un elemento importante dentro del proceso de adaptación a las sociedades de acogida. Pero, más allá de constatar la creación de iglesias étnicas como una tendencia importante entre las comunidades de inmigrantes, Hirschman propone que: «La mayoría de las iglesias, sinagogas y templos estadounidenses responden a las necesidades religiosas y espirituales, y atienden a las necesidades prácticas cotidianas de sus miembros. Este modelo ha ayudado a sucesivas generaciones de inmigrantes y a sus hijos a convertirse en estadounidenses» (Hirschman, 2004: 1229-1230). 
Conformar una iglesia étnica no representaría una actitud diferencialista de los inmigrantes con respecto a la sociedad de acogida, sino por el contrario, constituiría parte del proceso de estadounidización: los inmigrantes, como los estadounidenses, estarían siguiendo la pauta histórica característica del campo religioso estadounidense al agruparse en torno de iglesias étnicas. Dicho de otra forma, la organización social en torno de iglesias étnicas constituiría parte del proceso de incorporación de los inmigrantes, y dichas iglesias constituirían un recurso para la incorporación de los nuevos inmigrantes.

Una conclusión similar podría desprenderse del estudio de Levitt, quien a partir de su estudio con hindús de India, musulmanes de Pakistán, católicos irlandeses y protestantes de Brasil, todos ellos residentes en el área metropolitana de Boston, tras analizar el potencial de la religión en la construcción del compromiso cívico, sostiene que: «Religion is an under-utilized, positive force that social scientists and activists can no longer afford to ignore» (Levitt, 2008: 766). Así, la pertenencia a una comunidad, que se identifica a partir de creencias y prácticas religiosas compartidas, constituye una importante fuente de capital social, mismo que se ve potenciado ya que «faith communities come equipped with powerful resources and tools that encourage civic activism and shape its outcomes» (Levitt, 2008: 778).

En conjunto, los autores arriba citados han contribuido a mostrar que la relación religión/integración es compleja, puede llevar por distintos derroteros y no necesariamente es el origen de la división o el conflicto, pudiendo constituir, por el contrario, un importante recurso en los procesos de incorporación. Naturalmente, es necesario continuar contrastando los planteamientos arriba mencionados con realidades empíricas específicas para avanzar en la comprensión de las diversas estrategias mediante las cuales los inmigrantes movilizan sus creencias, prácticas, comunidades e instituciones religiosas en los procesos de incorporación a las sociedades de arribo.

Como una contribución en dicha dirección, en este artículo se analiza el papel específico de las creencias y las prácticas religiosas en los procesos de integración, a partir del estudio de caso de los mexicanos que radican en el área metropolitana de Los Ángeles. En las siguientes páginas trataremos de 
mostrar que, aun dentro de un grupo de inmigrantes relativamente homogéneo, como el que constituyen los mexicanos radicados en California, la forma específica en que se movilizan los referentes religiosos puede diferir notablemente. Estas diferencias obedecen tanto a las características específicas de los lugares de origen —en el ámbito religioso y con relación a la cultura política y organizativa - como a las características de mayor o menor apertura de las sociedades de destino.

El artículo está dividido en tres secciones. En la primera, comenzaremos por presentar las características específicas del contexto analizado, así como el diseño de la investigación. En la segunda parte, se presentan algunas de las características principales de los contextos religiosos de las comunidades de origen y de llegada de los inmigrantes. En la tercera parte describimos la forma específica en que los originarios de Zacatecas, Oaxaca y Veracruz movilizan sus referentes religiosos en los procesos de integración. Finalmente, concluimos reflexionando acerca de la posibilidad de avanzar hacia la construcción de una tipología de formas de relación religión-integración, que pudieran contribuir a la comprensión de este proceso en otros contextos.

\section{Zacatecanos, oaxaqueños y veracruzanos en los Ángeles}

El contexto de estudio y el diseño de la investigación

Si bien es cierto que en años recientes los lugares de destino de la migración mexicana se han diversificado, Los Ángeles ${ }^{1}$ sigue siendo un lugar paradigmático de la inmigración y un lugar privilegiado para la observación de los procesos de integración: es la segunda zona metropolitana más grande de Estados Unidos y la principal receptora de migración internacional. De su población inmigrante, los mexicanos constituyen el contingente mayor

${ }^{1}$ El área metropolitana de Los Ángeles está compuesta por cinco condados y cuenta con una población superior a los 17.7 millones de habitantes. La ciudad de Los Ángeles forma parte de este complejo urbano. Salvo indicación contraria, llamaremos Los Ángeles al área metropolitana en su conjunto. 
— poco más de 2.7 millones - conformando así la cuarta mayor concentración de población mexicana, después de la ciudad de México, Guadalajara y Monterrey. Del total de la población de Los Ángeles, el 14\% son inmigrantes mexicanos (Alarcón, Escala y Odgers, 2012).

La importancia de la presencia mexicana en Los Ángeles se deriva tanto de su magnitud como de su antigüedad, sin embargo, resultaría excesivo considerar a Los Ángeles como una ciudad hispana: a pesar de su origen como colonia española y la importancia de la inmigración proveniente de México, lo hispano dista mucho de ser un componente hegemónico y tan sólo ha logrado conquistar paulatinamente un espacio relevante a partir del movimiento chicano de los años setenta (Romo, 1983; González, 1994; Sánchez, 1993). Así, aunque desde finales de la década de 1990 la estación de radio más escuchada en la metrópoli transmita en español (Alarcón, 2008) o que diarios como La Opinión se cuenten entre los de mayor circulación, la población de origen mexicano sigue destacando por mantenerse en empleos precarios, constituir la minoría indocumentada de mayor tamaño, ocupar los más bajos índices de escolaridad, además de reproducir la segmentación étnica de la urbe (Charles, 2006).

Culturalmente, la población hispana en Los Ángeles constituye un conjunto diverso, en donde coexisten los descendientes de inmigrantes mexicanos y centroamericanos de segunda o tercera generación, con primo-migrantes arribados décadas atrás -incluyendo un subgrupo que ha adquirido la ciudadanía estadounidense-y con nuevos inmigrantes recién llegados, entre los que destacan quienes proceden de regiones con una escasa tradición migratoria.

Asumiendo esta heterogeneidad, dentro del trabajo que aquí se presenta examinamos la relación existente entre, por una parte, las creencias, prácticas y comunidades religiosas, y, por otra parte, la experiencia de integración.

Con la finalidad de observar de manera más precisa las diferencias existentes al interior de una población heterogénea, determinamos estudiar la experiencia de los inmigrantes mexicanos provenientes de tres entidades federativas diferentes: Zacatecas, Oaxaca y Veracruz.

$138 \frac{\text { SEGUNDO SEMESTRE } 2013}{\text { MIGRACIÓN Y DESARROLLO NÚM. } 21}$ 
La historia de la migración de los originarios del estado de Zacatecas hacia Estados Unidos es centenaria, y por lo mismo son un contingente emblemático de la región tradicional de migración a dicho país. En 2000, de acuerdo con Francisco Alba (2000), Zacatecas fue el estado con el mayor grado de intensidad migratoria de todas las entidades federativas de México. Delgado, Márquez y Rodríguez (2004: 165) afirman que hay más zacatecanos viviendo en Estados Unidos que en Zacatecas, ya que ellos estiman que habría 2.1 millones de residentes en Estados Unidos de origen zacatecano, que es una cifra muy superior a la población de Zacatecas, la cual es de solamente 1.4 millones de personas. La importancia de la migración zacatecana es tal que puede percibirse tanto por la construcción de comunidades de dicho origen, en Estados Unidos, como por el despoblamiento de amplias regiones de Zacatecas.

California ha sido el destino principal de los migrantes zacatecanos y en este estado destaca la zona metropolitana de Los Ángeles, sin embargo, diversos estudios revelan otros destinos en California (Mines, 1981; Nichols, 2006). Conviene también señalar el gran desarrollo de las organizaciones de migrantes zacatecanos, que a través de una confederación, dos federaciones y un gran número de clubes de migrantes (Home Town Associations) se han destacado por el desarrollo de proyectos productivos en las localidades de origen.

Para la realización de nuestro estudio, seleccionamos tres municipios del estado de Zacatecas que tienen una proporción importante de su población residiendo en la zona metropolitana de Los Ángeles. Éstos son Jerez, Nochistlán y Tepechitlán.

Debido al tiempo transcurrido desde su llegada, entre los zacatecanos a quienes entrevistamos la mayor parte había logrado regularizar su condición migratoria - ya sea que fueran ciudadanos estadounidenses o residentes permanentes legales-. Su condición laboral mostraba cierta movilidad ascendente e incluso varios de ellos se encontraban pensionados, después de haber laborado durante décadas en Estados Unidos.

Los inmigrantes originarios del estado de Oaxaca forman parte de una oleada migratoria posterior a la proveniente de la región centro-occidente de 
México. Si bien había ya algunos indicios de migración oaxaqueña a dicho país desde la primera mitad del siglo xx, estos migrantes comenzaron a llegar en grandes cantidades durante los años ochenta y noventa, distribuyéndose en diversos puntos de destino, particularmente en la región de Los Ángeles (Rivera Salgado, 2000; Zabin et al., 1993; Fox y Rivera Salgado, 2004).

Un factor clave para comprender la acelerada migración de oaxaqueños a California consiste en la transformación de la legislación migratoria con la llamada ley IRCA en 1986, que permitió que muchos inmigrantes oaxaqueños pudieran regularizar su estatus migratorio y con ello solicitar documentos legales para sus familiares mediante el procedimiento de reunificación familiar.

Es importante señalar que el estado de Oaxaca es la entidad mexicana más fragmentada cultural y étnicamente. Esta diversidad étnica se ve reflejada en las comunidades oaxaqueñas migrantes, entre quienes destaca la población mixteca y zapoteca.

A pesar de su migración relativamente reciente, su dispersión en el territorio en Estados Unidos, su condición étnica y social, y su incorporación a los estratos laborales más bajos en las regiones rurales y centros urbanos de California, los migrantes oaxaqueños han formado una amplia gama de comunidades y organizaciones binacionales (Fox y Rivera-Salgado, 2004; Escárcega y Varese, 2004; Stephen, 2007).

En California, los migrantes oaxaqueños se han orientado hacia las regiones agrícolas más importantes de dicha entidad, así como también en el sector servicios de los grandes centros urbanos (Nagengast y Kearney, 1990).

Las tres comunidades de migrantes oaxaqueños seleccionadas para la realización de este estudio son Tlacolula, Macuiltianguis — con población predominantemente zapoteca-y San Lorenzo Victoria — donde el componente mixteco es mayoritario-. La casi totalidad de los inmigrantes oaxaqueños entrevistados habían llegado a California como indocumentados, pero una proporción importante había logrado regularizar su condición migratoria, ya sea que hubieran obtenido la ciudadanía o que fueran residentes permanentes legales.

$140 \frac{\text { SEGUNDO SEMESTRE } 2013}{\text { MIGRACIÓN Y DESARROLLO NÚM. } 21}$ 
Diversos autores (Mestries, 2006; Rosas, 2008; Córdova, Núñez, Skerritt, 2008) coinciden en señalar que el principal detonador del flujo migratorio veracruzano fue la crisis agropecuaria y muy particularmente la caída de los precios de café y azúcar. Una proporción importante de los municipios donde la migración alcanza las tasas más elevadas se concentra en la región cañera del sur y en la región cafetalera del centro del estado. Se trata, en buena medida, de migrantes que abandonan sus localidades como parte de una estrategia de supervivencia familiar ante una situación de crisis.

Pese a la ausencia de tradición migratoria internacional, la comunidad veracruzana ha constituido vínculos con las organizaciones más estructuradas de migrantes mexicanos procedentes de otras regiones. Además, la migración veracruzana inició en un periodo en que los medios de comunicación se encuentran más desarrollados (Mestries, 2006: 264), y a la migración rural se ha sumado, en los últimos años, una importante participación de veracruzanos provenientes de los principales centros urbanos del estado.

La intensificación de la migración veracruzana coincide con el periodo del reforzamiento del control de la frontera México-Estados Unidos iniciado a finales de 1993, por lo que los veracruzanos se enfrentan a condiciones más adversas, una alta proporción de ellos no poseen documentos de residencia legal, sus redes sociales tienen un desarrollo más limitado y no cuentan con la experiencia migratoria de quienes proceden de otras entidades federativas.

Las tres comunidades seleccionadas para este estudio - Orizaba, Yanga y Playa Vicente- buscan dar cuenta de la diversidad en los perfiles de los migrantes veracruzanos: Yanga — con los índices de intensidad migratoria más altos del estado - constituye un ejemplo de emigración vinculada a la crisis agropecuaria; Orizaba muestra la experiencia migratoria de los veracruzanos urbanos, mientras que Playa Vicente, localizado al sur de Veracruz, permite observar la migración indígena de origen rural.

Para la realización del trabajo etnográfico se seleccionaron tres comunidades de origen de cada una de las entidades mencionadas que contasen con poblaciones significativas asentadas en la región de Los Ángeles. Se realizaron 90 entrevistas con inmigrantes provenientes de las nueve localidades 
seleccionadas, además de algunas decenas de entrevistas con informantes clave que aportaron elementos relevantes para el análisis. ${ }^{2}$

Conviene destacar que en promedio el año de establecimiento en Los Ángeles de nuestros entrevistados refleja la antigüedad de la migración de los tres estados seleccionados, por lo que se establecieron en la zona metropolitana de Los Ángeles en tiempos y coyunturas históricas distintas. Debido a las diferencias de sus lugares de origen, desde su llegada se distinguían también por haber sido socializados en campos religiosos diferenciados, además de presentar diferencias importantes en términos de culturas políticas, experiencias organizativas, tradiciones culturales, etcétera. Consecuentemente, el proceso de conformación de las comunidades zacatecana, oaxaqueña y veracruzana en Los Ángeles presenta diferencias que conviene señalar.

\section{El contexto Religioso de las localidades DE ORIGEN Y LLEGADA}

Si bien es cierto que México ha sido predominantemente católico desde los tiempos coloniales, también es un hecho que desde el último cuarto del siglo xx ha habido un importante proceso de diversificación religiosa, dando paso al crecimiento de otras denominaciones, principalmente evangélicas y bíblicas no evangélicas ${ }^{3}$ (Bastian, 1994; De la Torre y Gutiérrez, 2007). El proceso de diversificación religiosa presenta marcados contrastes regionales concentrándose en el sureste y las regiones fronterizas, mientras que la región del

2 Se trata de una muestra no probabilística, no aleatoria, construida a través del método de "bola de nieve», cuidando lograr una diversidad en características tales como edad, sexo, ocupación, estatus migratorio y estado civil. Si bien, en un primer momento el apoyo de los dirigentes de las asociaciones de migrantes constituyó un recurso fundamental para contactar a nuestros entrevistados, cuidamos también que la experiencia de quienes no forman parte de ninguna asociación fuera incorporada

${ }^{3}$ Este es el término que en el Censo nacional de población se asigna a Testigos de Jehová, Adventistas del Séptimo Día, y la Iglesia de los Santos de los Últimos Días (mejor conocida como Mormones).

$142 \frac{\text { SEGUNDO SEMESTRE } 2013}{\text { MIGRACIÓN Y DESARROLLO NÚM. } 21}$ 
centro occidente (donde se ubica Zacatecas) sigue constituyendo el núcleo duro del catolicismo mexicano (De la Torre y Gutiérrez, 2007; Hernández y Rivera, 2009).

Tanto Oaxaca como Veracruz presentan una distribución heterogénea de la diversificación religiosa, con algunas regiones en donde el cambio religioso ha sido acelerado en las últimas tres décadas y otras que mantienen un porcentaje de adscripción católica superior a la media nacional. Así, por ejemplo, si bien en Veracruz 83\% de la población se declaró católica en el censo de 2000, en cuatro municipios la población católica resultó minoritaria. En el caso de Oaxaca, para 2000 subsistían municipios en donde la totalidad de la población se declaró católica, mientras que en ocho municipios el catolicismo es minoritario.

Como se puede observar en la gráfica 1, los municipios de origen de nuestros entrevistados, sin representar casos extremos, reflejan bien la tendencia general de los estados en los que se ubican.

\section{GRÁFICA 1}

Porcentaje de población NO católica de los nueve municipios estudiados

Censo de Población y Vivienda (2000)

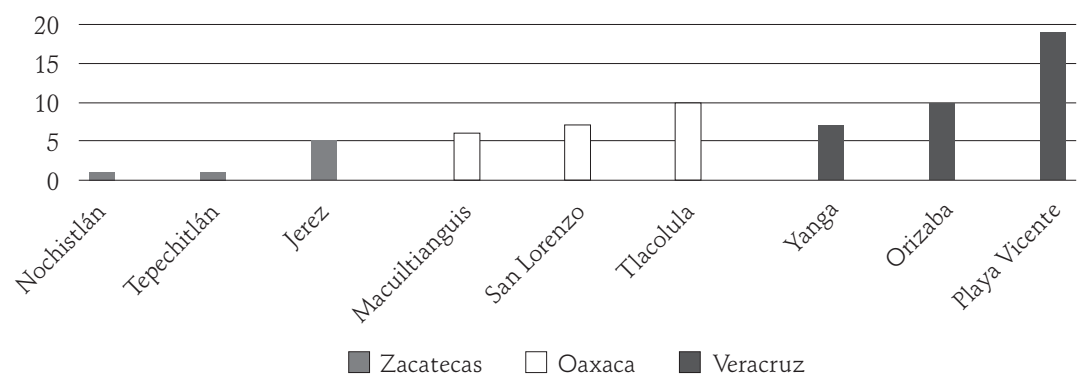

Esta distribución de la diversidad religiosa corresponde con las adscripciones expresadas por nuestros entrevistados: con una sola excepción, los zacatecanos se identificaron como católicos, mientras que cinco oaxaqueños dijeron no ser católicos. En contraste, entre los veracruzanos encontramos cerca de una cuarta parte de casos de creyentes no católicos, mientras 
que cerca de la mitad declararon haber asistido a celebraciones religiosas no católicas o tener familiares cercanos adscritos a otra denominación religiosa. Las adscripciones no católicas de los veracruzanos entrevistados se concentran en denominaciones protestantes y evangélicas, además de dos casos de conversión a la Iglesia de Jesucristo de los Últimos Días (Mormones).

Es interesante señalar que la mayoría de los entrevistados — de los tres estados- expresaron tener vecinos o compañeros de trabajo adscritos a otras denominaciones, siendo las más citadas las «cristianas», ${ }_{4}^{4}$ Testigos de Jehová y mormones, como se muestra en la gráfica.

\section{GRÁFICA 2}

Denominaciones religiosas de vecinos, amistades o compañeros de trabajo mencionadas por nuestros entrevistados

(Los Ángeles, 2008)

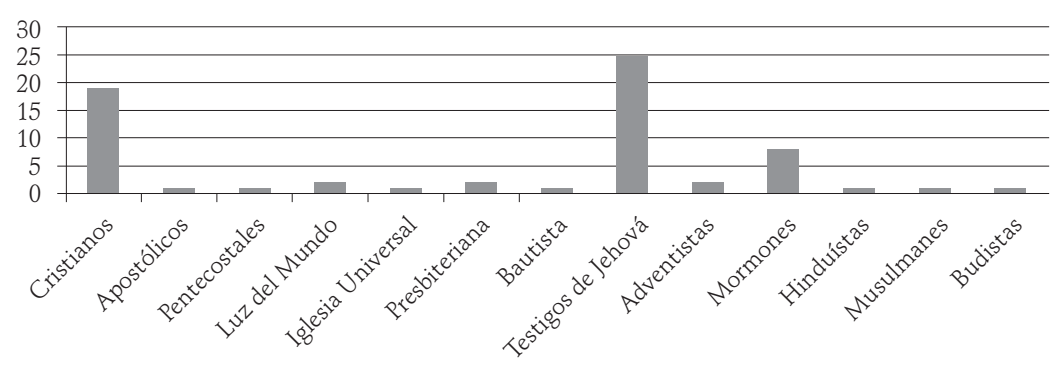

Ahora bien, más allá de la adscripción mencionada, aun dentro del catolicismo encontramos diferencias importantes en la forma y frecuencia con la que la práctica religiosa es realizada. Como veremos a continuación, destaca una mayor práctica religiosa cotidiana entre los zacatecanos, una identificación católica mayoritaria pero relativamente poco practicante por parte de los oaxaqueños, y una mayor diversificación religiosa — acompañada de una mayor individualización en la práctica por parte de los veracruzanos.

${ }^{4}$ Este término es comúnmente empleado para nombrar a las iglesias evangélicas, entre las cuales las denominaciones pentecostales son frecuentes.

$144 \frac{\text { SEGUNDO SEMESTRE } 2013}{\text { MIGRACIÓN Y DESARROLLO NÚM. } 21}$ 


\section{FORMAS DE RELACIÓN RELIGIÓN/INTEGRACIÓN}

Zacatecanos: catolicismo nominal e identidad individual

A partir de las entrevistas realizadas, el primer rasgo distintivo de la práctica religiosa zacatecana — después de la adscripción unánime al catolicismo- lo constituye la frecuencia de la práctica religiosa. La mayor parte de los zacatecanos declararon asistir a misa al menos una vez por semana, pero incluso son frecuentes los casos en que se refiere una participación más asidua, o un compromiso específico — que trasciende la asistencia a la misa — adquirido dentro de la ritualidad cotidiana. Es el caso de doña Jacinta, quien menciona: "yo voy seguido a la iglesia, soy ministro de eucaristía, me gusta ir porque yo me relajo en la iglesia y [además de la misa dominical] todos los martes voy a la oración»; o don Ricardo y su esposa «no fallamos, vamos todos los domingos, también entre semana cuando tenemos oportunidad de ir».

Además de los ejemplos citados, encontramos referencias a la participación en grupos de oración, en el catecismo y en el coro de las respectivas iglesias. Se mencionan también los altares domésticos y la importancia acordada a los rezos diarios: «trato de ser respetuoso con Dios nuestro señor, [...] a misa solamente voy los domingos y cuando voy a tocar, pero sí rezo diario, rezo hasta 2 o 3 rosarios, voy en el carro y voy rezando» (Ladislao).

Conviene destacar que estas formas de participación se realizan principalmente de manera individual. Es decir, si bien los grupos de oración, la participación en el coro de la iglesia o la asistencia a la misa son prácticas religiosas que permiten socializar y progresivamente crean comunidad, cada uno de ellos asiste a título individual, no como miembro de un poblado o una región en particular, ni como miembro de un sistema de cargos, o como devotos de un santo particular, como sucede frecuentemente en el caso de los oaxaqueños.

Un caso ilustrativo de esta práctica individual —aunque anclada en las figuras patronales de las localidades de origen - lo constituye el testimonio del señor Abelardo: «La Virgen de Guadalupe es la Patrona de Jomulquillo, 
de mi rancho, yo aquí la tengo, ahí en mi baño, y tengo al Santo Niño de Atocha... y tengo a cristo, y ahí mismo le prendo yo sus veladoras, tengo un pequeño altarcito ahí». Otro ejemplo de práctica religiosa individual, frecuentemente mencionada por los zacatecanos, es el encomendarse y rezar cotidianamente para agradecer a Dios y/o para pedir su ayuda y protección.

Ahora bien, debido a la importante segregación residencial del área metropolitana de Los Ángeles (Waldinger y Bozorgmehr, 1996; Charles, 2006; Alarcón, Escala y Odgers, 2012), es frecuente que los entrevistados asistan a misas en español, en las que conviven principalmente con fieles de diversas regiones de México, con méxicoamericanos, y con inmigrantes centroamericanos. Esta característica es consistente con lo reportado por el Pew Research Center (2007), en donde se identifica que la gran mayoría (87\%) de los hispanos que viven en los Estados Unidos, asisten a iglesias en las cuales el servicio religioso se desarrolla en español.

La adscripción al catolicismo es vista entonces como un referente de identidad personal que los vincula con una referencia religiosa universal, pero al mismo tiempo les permite construir espacios de interacción intraétnicos, en donde el catolicismo «latino», e incluso "a la mexicana» ha logrado establecerse.

Adicionalmente a la práctica religiosa cotidiana, algunos entrevistados señalaron participar en la celebración a la Virgen de Guadalupe el día 12 de diciembre, ya sea que su participación se limite a la contribución monetaria y a la asistencia a la celebración, o que participen activamente en la organización de la misma. A diferencia de los ejemplos anteriores, en este caso se trata de una práctica colectiva que recrea una comunidad preexistente, sin embargo se trata ante todo de una identidad nacional — no local ni regional-y en la cual se coordinan con católicos originarios de diversas regiones de México. En este sentido, Martina lamenta que los zacatecanos no hayan logrado organizarse en torno de una devoción específicamente zacatecana — que trascienda las identificaciones locales - como podría ser el Santo Niño de Atocha, y que la devoción siga siendo, literalmente, cada quien para su Santo. 
Oaxaqueños: la construcción de una comunidad transnacional

Este panorama, sin embargo, se transforma si observamos la práctica religiosa de la comunidad oaxaqueña. Aunque con algunas excepciones, la práctica religiosa cotidiana - y en particular la asistencia a misa - parece ser menos intensa: "somos católicos, pero a la iglesia vamos de vez en cuando» (Esteban); "no soy de las que voy cada 8 días, no me la vivo en la iglesia... cada mes quizás (Azhalea); "[voy a misa] cada que puedo, sólo voy los domingos que descanso, porque a veces trabajo» (Nora).

En cambio, el catolicismo oaxaqueño parece volcarse de intensa en las prácticas colectivas, reproduciendo la lógica organizativa de las comunidades de origen mediante la transnacionalización del sistema de cargos tradicional, extendiendo esta particular forma de práctica religiosa y organizativa entre los oaxaqueños migrantes y las segundas generaciones establecidas en California. De esta forma es posible identificar los tiempos y espacios excepcionales en los que la comunidad local se congrega: la iglesia de Santa Cecilia, la devoción al Señor de Tlacolula en San Sebastián, así como las celebraciones a las Virgen de la Soledad y del Rosario, constituyen algunos de los pilares relevantes en la construcción de vínculos comunitarios transnacionales.

Durante el trabajo de campo, pudimos asistir a la celebración de la Virgen del Rosario, en la que participaron cerca de un centenar de fieles oaxaqueños. El sistema de cargos replicaba la organización tradicional y se vinculaba estrechamente con las responsabilidades adquiridas en las comunidades de origen. La celebración comienza con un desayuno en casa de la mayordoma, después el grupo sigue la Calenda, donde los fieles desfilan llevando sus trajes tradicionales; en seguida viene la Marmota, especie de gigante de alambre y cartón vestido con ropa de tela, que baila al ritmo de los sones tradicionales. Continúa la procesión con la Virgen, la llegada a la iglesia, la misa y finalmente la fiesta, con comida tradicional y bailes regionales. Esta celebración se realiza simultáneamente en Oaxaca, en Los Ángeles y en Las Vegas.

Con relación a la misa oaxaqueña, además de la celebración en la parroquia de Santa Cecilia, Guillermina explica: "[la iglesia] se llama San Sebastián, es 
una iglesia católica, [...] tiene dos años que trajeron a un santito que es nuestro Santo Patrón, el Señor de Tlacolula, de donde yo soy originaria y apenas hace un año le empezaron hacer la misa oaxaqueña con banda de música, con banda de viento».

Por la gran cantidad de participantes congregados en estas ocasiones especiales, pudimos observar que son éstas —más que la práctica religiosa cotidiana o individual - las que movilizan a los católicos oaxaqueños mediante vastas redes transnacionales. Conviene señalar que las motivaciones para participar en estos eventos especiales no se limita al ámbito espiritual, e involucra también el deseo por reencontrarse con paisanos, disfrutar de prácticas culturales específicas — comida tradicional, música, danza, etcétera-y por socializar a las segundas generaciones dentro de los referentes de las localidades de origen.

En dicho sentido, es relevante el contraste entre la práctica religiosa católica de los zacatecanos y la de los oaxaqueños, que está íntimamente ligada a la reproducción étnica y comunitaria, tanto en sus aspectos identitarios como en la dimensión organizativa, fenómeno que ha sido analizado por diversos autores en otros contextos (Rivera Sánchez, 2004; Odgers, 2006; Odgers y Ruiz Guadalajara, 2009).

La construcción de estos espacios específicos de la religiosidad oaxaqueña se ha producido, sin duda, mediante la tensión y la negociación. Un ejemplo claro de ello es la transformación de la iglesia Santa Cecilia antes citada, en un espacio de congregación de la comunidad oaxaqueña. Esta iglesia, fundada en 1927, congregaba principalmente a la población blanca hasta la década de 1960, cuando la importante presencia de la población negra en la región comenzó a reflejarse en la feligresía asistente a las misas dominicales; pero es a partir de los noventa cuando la población latina $-\mathrm{y}$ específicamente oaxaqueña - se volvió mayoritaria, de manera que no solamente el español ocupó un lugar central en la liturgia, sino también las celebraciones e imágenes religiosas veneradas.

Esta transformación es interpretada por el padre Luigi Zanotto como un elemento positivo en el proceso de integración, quien sostiene que «Esta iglesia es hoy la definición de una parroquia... que es la comunión de las

$148 \frac{\text { SEGUNDO SEMESTRE } 2013}{\text { MIGRACIÓN Y DESARROLLO NÚM. } 21}$ 
comunidades» (Quiñónez, 2008). Por su parte, el señor Heriberto, originario de Oaxaca, menciona «Esta iglesia nos ofrece la gran oportunidad de... abrirnos hacia el mundo más amplio» (Quiñónez, 2008).

Es decir, estaríamos frente a un caso de integración cultural desde la lógica de la búsqueda del reconocimiento de las prácticas culturales particulares dentro de un contexto heterogéneo, en el que han logrado construir un espacio particular, vinculándose con otros sectores de la sociedad, y reconstruyendo simultáneamente vínculos transnacionales con las comunidades de origen. Las creencias y prácticas religiosas son movilizadas aquí como un recurso para la construcción de comunidades transnacionales, que se incorporan a la sociedad de destino sin romper sus lazos con las comunidades de origen.

Veracruz: los nuevos caminos de la integración

En el caso de los veracruzanos, como se señaló con anterioridad, la primera característica que destaca es la importante proporción de quienes no se identifican como católicos. Esta característica se ve reforzada por la gran diversidad en las formas de practicar, en donde destaca una mayor individuación de la creencia (Hervieu-Léger, 1999), dando cabida a interpretaciones personales de la relación con lo sagrado, con la comunidad y con las instituciones religiosas.

Aunque son escasos los veracruzanos que reportan una asistencia frecuente a los servicios religiosos, sí destaca para algunos de ellos — especialmente para los originarios de una localidad zapoteca del municipio de Playa Vicente-, la importancia de las promesas ofrecidas a los santos patronos locales y la necesidad de encomendarse en momentos de peligro. Es el caso de Ciro, quien narra que el esfuerzo por formar un grupo musical había sido infructuoso hasta que el maestro de música que los asesoraba les espetó:

«之ंTiene fe?»—preguntó el maestro— «iSíl»—contestamos todos— «Pues vayan y hagan una misa y hablen con la patrona de los músicos, [díganle que] ustedes 
quieren realizar su sueño y le prometen que van a ir a tocar, ya ustedes sabrán cuándo». Y sí fuimos y pagamos una misa con el cura. Todos le prometimos ir a tocar [a Playa Vicente], ahí es fiesta de la patrona [Santa Cecilia] el 22 de noviembre y sí, sí fuimos.

Los integrantes del grupo sostienen que el éxito del conjunto musical - con el que obtienen ingresos adicionales a los de su salario como obreros en una fábrica textil - se debe a la intercesión de la Virgen de Santa Cecilia, patrona de los músicos y de su pueblo natal, para quien profesan una profunda devoción, que los ha motivado a volver al pueblo para realizar conciertos en honor a la Virgen, aun a pesar de su estatus indocumentado, el elevado costo de los coyotes y la clara percepción que ellos tienen del incremento en la peligrosidad del cruce fronterizo.

Sin embargo, entre los católicos veracruzanos encontramos también perspectivas más pragmáticas e individualizadas de la religión. Es el caso de Edgardo, quien sostiene que va a misa únicamente «cuando Dios me lo permite».

Otra perspectiva de la individuación de la creencia es la que explica Adelaida, quien, si bien tuvo la oportunidad de estudiar algunos semestres en la universidad, actualmente trabaja en un hotel como recamarera, y como empleada doméstica por cuenta propia:

[Como católica] tengo que estarle trabajando, pero dentro de la Biblia, en lo que yo he buscado. También en el lenguaje metafórico que es la Biblia y todo esto, hay algo que yo no lo he mirado en otros libros... y se los digo [a los sacerdotes católicos], porque todo mundo tiene derecho a buscar y estudiar, y a plantearse sus patrones de planeación. [...] [Por ejemplo] para mí Adán y Eva son los que marcaron la era del homo sapiens, entonces yo tengo que estar reestructurando todo esto con antropología, sociología y filosofía.

Para Adelaida, la experiencia de la migración ha significado, entre otros aspectos, el distanciamiento de patrones tradicionales de control social y el 
encuentro con un catolicismo más diverso e incluyente. A manera de ejemplo, menciona el «movimiento de gays, lesbianas, bisexuales y transexuales católicos, sus familias y sus allegados», al que pudo conocer a través de la iglesia católica a la que asiste.

Entre los veracruzanos no católicos, encontraríamos dos casos significativos de la relación religión/integración. Por una parte Celene señala que la iglesia presbiteriana a la que asiste es un espacio que le permite socializar con la población anglosajona y conocer mejor su manera de pensar. Celene valora particularmente el potencial que la socialización con población anglosajona puede tener para sus hijos.

La iglesia atiende principalmente a tres grupos étnicos, que se ven reflejados en los idiomas en que se oficia: «los coreanos tienen su servicio aparte... primero es [el oficio] en español, luego entran los americanos y la hacen en inglés-español, luego nos salimos los hispanos y la hacen solamente en inglés». Si bien la familia de Celene comenzó asistiendo al oficio en español, rápidamente transitaron hacia el oficio bilingüe en donde "algunos americanos hasta ya se saben algunos cantos en español». Gracias a su actitud participativa, antes de haber cumplido un año en la iglesia fue invitada a participar como «anciana gobernante», en cuya función ha sido muy activa, proponiendo, por ejemplo, que la iglesia se declarara santuario para inmigrantes indocumentados. Así, resulta interesante observar que a pesar de la segregación étnica prevaleciente en la iglesia, Celene ha logrado desarrollar, en su interior, una estrategia de integración.

Por otra parte, la señora Rita, inmigrante indocumentada de origen zapoteca, señala que ella finalmente decidió «guardar a sus Santitos» e integrarse a la comunidad mormona, debido a que aprendió a leer y escribir gracias a los misioneros que le daban clases cada semana en su departamento del Este de Los Ángeles. Pero además, un aspecto primordial en su proceso de conversión fue el apoyo recibido por parte de los misioneros para salir de un contexto de violencia intrafamiliar: las visitas de los mormones le permitieron adquirir la confianza y la información necesarias para denunciar a su esposo — quien finalmente fue deportado- poniendo fin de este modo a más de dos décadas de violencia física y psicológica. 
Hoy, la señora Rita estima que la «religión de los mormones» es la que mejor corresponde a la realidad en la que ahora vive y la que le ayudará mejor a salir adelante en ese contexto de vida, por lo que después de más de un año de recibir las visitas de los misioneros mormones, decidió dar el paso hacia la conversión y «entregarse al Padre Celestial».

En este caso es interesante observar que la comunidad mormona permite a la señora Rita adquirir herramientas concretas para integrarse a la sociedad estadounidense y lograr cierta movilidad social: además de recibir clases de lectoescritura, Rita conoció los procedimientos para denunciar la violencia familiar, comenzó a aprender inglés y amplió sus redes sociales a través de las «amigas de la iglesia», lo que implicó también la ampliación de una red de compradores de la comida típica veracruzana que vende para subsistir, incrementando así sensiblemente sus ingresos. A pesar de tener aún un gran aprecio por la fiesta patronal católica de su pueblo, para la que acostumbraba enviar contribuciones monetarias, señala:

Ahora no sé qué voy a hacer [con la contribución a la fiesta patronal] porque yo ya guardé mis santitos. Me dice mi hija i̇porqué hace eso? [y yo respondo]: ya viví mucho tiempo teniendo fe en mis santitos pero veo que no me dieron nada. Apenas llevo un mes que me entregué a padre celestial [conversión mormona] y ya veo lo centavos. Ya vivo mejor. Ya vivo bien. Ya no lloro. Ya tengo mucha amiga de la iglesia.

\section{CONCLUSIONES: HACIA UNA TIPOLOGÍA DE FORMAS DE RELACIÓN RELIGIÓN/INTEGRACIÓN}

A partir de lo expuesto en los apartados anteriores, observamos que la práctica religiosa parece ser un referente importante para la integración de zacatecanos, oaxaqueños y veracruzanos, pero por razones diferentes.

La diferencia parece relacionarse, entre otros aspectos, con las características del campo religioso del lugar de origen, que se reflejarán en la forma en que cada persona interpreta y se adapta al campo religioso angelino.

$152 \frac{\text { SEGUNDO SEMESTRE } 2013}{\text { MIGRACIÓN Y DESARROLLO NÚM. } 21}$ 
Las experiencias estudiadas permiten identificar al menos cuatro patrones diferenciados, que podrían constituir tres tipos - en el sentido weberiano- de formas de relación religión-integración.

Por una parte, la experiencia zacatecana muestra la movilización de una identificación personal católica para la participación en una comunidad que es percibida desde su carácter universalizante - desvinculado de la especificidad étnica o de los referentes devocionales de las localidades de origen. Pese a ello, la importante segregación residencial tiene como corolario que quienes acuden al catolicismo como referencia incluyente, en busca de su incorporación a una iglesia "global», vean sus esfuerzos limitados y terminen asistiendo a misa en parroquias exclusiva —o mayoritariamente- hispanas.

En un segundo momento, el caso oaxaqueño ejemplifica la conformación de comunidades transnacionales, estructuradas a partir de un componente étnico-religioso, en donde la identificación con la comunidad de origen resulta fundamental. Dicha identificación es movilizada como un recurso para la incorporación en la sociedad de acogida, reivindicando la especificidad cultural en el espacio público y adaptándolo a la lógica de las iglesias étnicas, referidas por Hirschman (2004).

El caso veracruzano muestra cómo la diversidad de denominaciones y formas específicas de comprender la práctica religiosa $-\mathrm{y}$ la relación del individuo con las creencias, comunidades e instituciones religiosas- se ve reflejada en una igualmente diversa forma de movilizar lo religioso en los procesos de integración.

Así, si bien algunos casos veracruzanos se aproximan a la experiencia oaxaqueña en la movilización de la identificación a los santos patrones locales para la construcción de comunidades transnacionales, existen al menos otros dos tipos de relación que conviene destacar.

Por una parte, encontramos una versión más individualizada de la identificación católica, en donde el creyente ejerce una mayor capacidad crítica para construir una interpretación personal de la creencia, una versión particular de la práctica y para participar así en una comunidad que es percibida como más abierta e incluyente. 
Por otra parte, los casos de conversión religiosa muestran una voluntad explícita por construir una estrategia de integración a partir de la movilización de los referentes religiosos, ya sea mediante la búsqueda de integración a una iglesia anglosajona, o bien, mediante la ponderación pragmática del potencial de las diferentes denominaciones religiosas a las que tiene acceso para la construcción de un camino de supervivencia y movilidad social.

En suma, resulta interesante observar que cada una de estas estrategias ha permitido a los inmigrantes participar activamente en el campo religioso californiano y establecer nuevos vínculos con la sociedad de destino, ya sea mediante su participación en la liturgia cotidiana, la organización de celebraciones extraordinarias, o mediante la aproximación a nuevas denominaciones.

\section{Bibliografía}

AlARCón, Rafael (2008), «Los inmigrantes mexicanos y el mercado de trabajo en Los Ángeles al inicio del siglo XXI», en Cardenio Bedoya, Flavia Belpoliti y Marc Zimmerman (coords.), Orbis/Urbis Latino: Los Hispanos en las ciudades de los Estados Unidos, Houston, TX, Global casa/lacasa Publications, University of Houston, pp. 182-192.

Alarcón, R., L. Escala y O. Odgers (2012), Mudando el hogar al Norte, El Colef, 416 pp.

Alba, Francisco (2000), «Migración internacional. Consolidación de patrones emergentes», Demos, núm. 13, Carta demográfica sobre México 2000. Universidad Nacional Autónoma de México/Fondo de Población de las Naciones Unidas/ Instituto Nacional de Estadística, Geografía e Informática/El Colegio de México.

Bastian, J. P., (1994), Protestantismos y modernidad latinoamericana. Historia de unas minorías religiosas activas en América Latina, México, Fondo de Cultura Económica.

Charles, C. Z. (2006), Won't You Be My Neighbor? Race, Class and Residence in Los Angeles, Nueva York, Russell Sage.

Córdova, R., C. Núñez y D. Skerritt, (2008), Migración internacional, crisis agrícola y transformaciones culturales en el centro de Veracruz, Cemca, Universidad Veracruzana/Plaza y Valdés/Conacyt.

$154 \frac{\text { SEGUNDO SEMESTRE } 2013}{\text { MIGRACIÓN Y DESARROLLO NÚM. } 21}$ 
De la Torre, R. y Cristina Gutiérrez (eds.) (2007), Atlas de la diversidad religiosa en México, México, El Colegio de Jalisco, El Colef, Ciesas, El Colegio de Michoacán, Secretaría de Gobernación, Universidad de Quintana Roo, 400 pp.

Delgado, R., H. Márquez y H. Rodríguez (2004), "Organizaciones transnacionales de migrantes y desarrollo regional en Zacatecas», Migraciones Internacionales, Tijuana, México, El Colegio de la Frontera Norte, vol. 2, núm. 4, julio-diciembre, pp. 159-181.

ESCÁRCEGA, S. y S. Varese (2004), La ruta mixteca, colección La Pluralidad Cultural en México, del Programa Universitario México Nación Multicultural, UnAm.

Fox, J. y G. Rivera-Salgado (2004), «Introducción», en Jonathan Fox y Gaspar RiveraSalgado (coords.), Indígenas mexicanos migrantes en los Estados Unidos, México, H. Cámara de Diputados LIX Legislatura/Universidad de California Santa Cruz/Universidad Autónoma de Zacatecas/Miguel Ángel Porrúa.

González, Gilbert G. (1994), "Chicano History: Transcending Cultural Models», Pacific Historical Review, Berkeley, CA, David Johnson et al. (eds.), vol. 63, núm. 4, noviembre, pp. 469-497.

Herberg, Will [1955] (1985), Protestant, Catholic, Jew. An Essay on Americas Religious Sociology, Chicago, University of Chicago.

Hernández, Alberto y Carolina Rivera (eds.) (2009), Regiones y religiones: estudios de la transformación sociorreligiosa, Tijuana, El Colegio de la Frontera Norte, CIESAS. Hervieu-Léger, Danièle (1999), Le Pèlerin et le converti. La religion en mouvement, París, Flammarion.

Hirschman, C. (2004), "The Role of Religion in the Origins and Adoptation of Immigrant Groups in the United States», International Migration Review, XXXVIII, núm. 3.

Huntington, S. (2004), Who we are? The challenges to America's National Identity, Simon \& Schuster.

LevitT, P. y Nina Glick Schiller (2004) «Conceptualizing Simultaneity: A Transnational Field Perspective on Society», International Migration Review, vol. 38 (4), pp. 1002-1039.

(2008), "Religion as a Path to Civic Engagement and Civically-Infused Religion", Racial and Ethnic Studies, 31(4): 766-791.

Mestries Benouet, Francis (2006), "Migración internacional y campesinado cafetalero en México: Fases, circuitos y trayectorias migratorias», Análisis Económico, México, vol. xxi, núm. 46, primer cuatrimestre, pp. 263-289. 
(2003), «Crisis cafetalera y migración internacional en Veracruz», Migraciones Internacionales, Tijuana, México, El Colegio de la Frontera Norte, vol. 2, núm. 2, julio-diciembre, pp. 121-148.

Mines, Richard (1981), Developing a Community Tradition of Migration: A Field Study in Rural Zacatecas, Mexico, and California Settlement Areas, Monographs in U.S.Mexican Studies \#3, Program in United States-Mexican Studies, San Diego, University of California.

Nagengast, C. y M. Kearney (1990), «Mixtec Identity, Political Consciousness, and Political Activism», Latin American Research Review, Philip Oxhorn (ed.), Montreal, vol. 25, núm. 2.

Nichols, Sandra L. (2006), Santos, duraznos y vino. Migrantes mexicanos y la transformación de Los Haro, Zacatecas, y Napa, California, México, Universidad Autónoma de Zacatecas/Miguel Ángel Porrúa.

ODgers, O. (2006), «Movilidades geográficas y espirituales: cambio religioso y migración México-Estados Unidos», Economía, Región y Sociedad, vol. vI, núm. 22, pp. 399-430.

y J.C. Ruiz Guadalajara (coord.) (2009), Migración y creencias: pensar las religiones en tiempos de movilidad, México, El Colegio de la Frontera Norte, E1 Colegio de San Luis, Miguel Ángel Porrúa, 576 pp.

Pew Research Center (2007), Changing Faiths: Latinos and the Transformation of American Religion, consultado en línea en http://www.pewhispanic.org/files/reports/75.pdf

Quiñónes, Sam (2008), "A Church is Reborn», Los Angeles Times, sección Local, Los Ángeles, 10 de febrero, en <articles latimes.com/2008/feb/10/local/me_oaxacans10>, 17 de noviembre de 2009.

Rivera-Salgado, G. (2000), "Transnational Political Strategies: The Case of Mexican Indigenous Migrants", en Foner, Rumaut y Gold (eds.), Immigration Research for a New Century: Multidisciplinary Perspectives, Nueva York, Russel Sage Foundations, pp. 134-156.

Rivera Sánchez, L. (2006) «Cuando los Santos también migran: Conflictos transnacionales por el espacio y la pertenencia», Migraciones internacionales, vol III, núm. 4. (2004), «Inmigrantes mexicanos en Nueva York: construyendo espacios de organización y pertenencia comunitaria», en J. Fox and G. Rivera Salgado, Indígenas mexicanos migrantes en los Estados Unidos, México, Cámara de Diputados LIX Legislatura, Universidad de California Santa Cruz, Universidad Autónoma de Zacatecas, Miguel Ángel Porrúa.

$156 \frac{\text { SEGUNDO SEMESTRE } 2013}{\text { MIGRACIÓN Y DESARROLLO NÚM. } 21}$ 
Romo, R. (1983), East Los Angeles: History of a Barrio, United States, University of Texas Press.

Rosas, Carolina (2008), Única autora: Varones al son de la migración. Migración internacional y masculinidades de Veracruz a Chicago, México, El Colegio de México.

SÁNCHEZ, George (1993), Becoming Mexican American. Ethnicity, Culture and Identity in Chicano Los Angeles. 1900-1945, Oxford, Oxford University Press.

Stephen, Lynn, (2007), Transborder Lives: Indigenous Oaxacans in Mexico, California and Oregon, Durham, NC, Duke University Press.

WALDINGER, Roger y Mehdi Bozorgmehr (1996), «The Making of a Multicultural Metropolis», en Roger Waldinger y Mehdi Bozorgmehr (eds.), Ethnic Los Angeles, Nueva York, Russell Sage Foundation, pp. 3-37.

Warner, S. (1993), «Work in Progress toward a New Paradigm for the Sociological Study of Religion in the United States», The American Journal of Sociology (98)5.

Zabin, Carol, Michael Kearney, Anna García, David Runsten y Carole Nagengast (1993), A New Cycle of Poverty, Mixtec Migrants in California Agriculture, Davis, CA, California Institute for Rural Studies.

Zamudio, P., A. M. Chávez y C. Rosas (2007), «La migración en el estado de Veracruz, una visión desde sus municipios», en Agustín Escobar Latapí (coord.), Nación, estado, comunidad: Consolidación y emergencia en la emigración mexicana, México, Ciesas. 
